\section{A view from the Sunda arc}

SIR - Plank and Langmuir ${ }^{1}$ argue that the sedimentary flux down subduction zones of elements like $\mathrm{Ba}, \mathrm{Sr}, \mathrm{K}, \mathrm{Rb}, \mathrm{Cs}, \mathrm{La}$, Th and $U$ is reflected by the abundances of these elements in the volcanic outputs from the arc once the effects of melting are taken into account. They illustrate their argument with data for eight volcanic arcs, including the Sunda arc, for each of which they compare an average basalt composition with a calculated sediment flux based on the rate of subduction and on the bulk composition of a representative sediment section.

For the Sunda arc, Plank and Langmuir calculate an average basalt composition with about $1 \% \mathrm{~K}$ from data for six central Javanese volcanoes. But it seems pointless to calculate an average Sunda basalt when it is known that the abundances of $\mathrm{K}$ group elements in mafic volcanics in Sunda volcanoes vary along the $\operatorname{arc}^{2}$ as well as across $i^{3}$ : they are low in west Javanese volcanoes but increase going eastwards as far as central Java, then at about $112^{\circ} \mathrm{E}$ revert to relatively low contents but again increase eastwards as far as Sumbawa. Therefore, the abundances of $\mathrm{K}$ (which in the Sunda arc are well-correlated with $\mathrm{Rb}$, $\mathrm{Sr}, \mathrm{Nb}$, Th and La abundances) in mafic (6\% $\mathrm{MgO}$ ) magma compositions legitimately selected as representative of various sectors of the Sunda arc could vary, using Plank and Langmuir's approach, from 0.5 to $3.00 \% \mathrm{~K}$ depending on which sector of the arc one selects the volcanoes. How can Plank and Langmuir explain this along-arc variation as a consequence mainly of sediment flux?

I also wonder how good the correlation really is between $\mathrm{K} / \mathrm{Na}$ and $\mathrm{Ba} / \mathrm{Na}$ values which Plank and Langmuir calculate from their average basalt compositions, and their calculated sediment fluxes of $\mathrm{K}$ and $\mathrm{Ba}$. This correlation is the main evidence they cite in support of their general argument (Fig. 3 of ref. 1). For the Sunda basaltic data point, Plank and Langmuir averaged D. J. Whitford's data for six central Javanese volcanoes to get values of 0.34 for their $\mathrm{K} / \mathrm{Na}$ parameter and 90 for their $\mathrm{Ba} / \mathrm{Na}$ parameter. But, for their six selected Javanese volcanoes, the values of the $\mathrm{Ba} / \mathrm{Na}$ parameter include two at 35 and 36 , and two at 141 and 206 , so that four of the six volcanoes fall outside the range of their averages for all eight arcs. Similarly, the values of their $\mathrm{K} / \mathrm{Na}$ parameter include two at 0.13 and 0.16 , and two at 0.50 and 0.66 , again outside the range of their averages for the eight arcs.

Not only are Plank and Langmuir placing a lot of faith in their selection of the volcanoes as representative and in their averaging approach, but the range of values they averaged is actually also representative of real variation between different parts of the arc, so that their own approach suggests that in the Sunda arc there might instead be a very poor correlation between basalt composition and sediment flux, at least for $\mathrm{Ba}$ and $\mathrm{K}$.

It seems to me that Plank and Langmuir's explanation fails to account for one of the most interesting geochemical features of the world's most active arc. I would be interested to know how it looks when viewed from the seven other arcs.

\section{R. Varne}

Department de Petrologie,

Université Pierre et Marie Curie,

75252 Paris, Cedex 05, France

Present address: Department of Geology. University of Tasmania, Hobart, Australia 7005.

Plank And Langmuir RePly - We thank Varne for focusing attention on an important aspect of the Sunda volcanics: the extreme geochemical variability. There are three significant issues he raises: (1) the validity of the Sunda average; (2) the validity of averages for the other arcs we considered; and (3) the origin of variability among volcanoes from a single arc. We shall address these issues here briefly; they are discussed in more detail in ref. 4.

Our general goal ${ }^{1}$ was to test whether sedimentary input affects volcanic output. We would like to investigate this relationship at all length scales, but current limited sampling of the sea floor near trenches restricts us to examing relationships at the global scale. Thus we focused on inter-arc variations, which required us to calculate averages for the volcanic output at each arc. Large variations within populations does not invalidate comparison of the means of the populations. We share Varne's concern about the Java average; as shown by the \pm 1 sd error bars in Fig. 3 of ref. 1 , it is the most uncertain of the averages and deserves scrunity. For the Sunda arc,

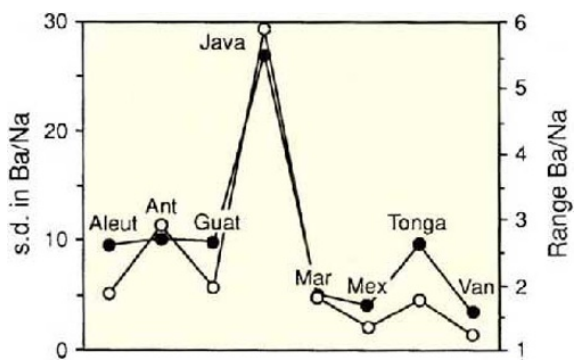

Uncertainty in the mean $\mathrm{Ba} / \mathrm{Na}$ of eight volcanic arcs, expressed as 1 s.d. of the mean (solid symbols) and as the total range (high value/low value) (open symbols). Java is clearly anomalous. Other arcs include the Eastern Aleutians (Aleut), Lesser Antilles (Ant.), Guatemala/El Salvador, (Guat), Marianas (Mar), Mexico (Mex), Tonga and Vanuatu (Van). tectonic constraints and data availability limited us to volcanism on Java, where continent collision has not yet begun, and to six volcanoes for which geochemical data exist on mafic samples ${ }^{5}$. The variation in these six Javanese volcanoes is as large as the global range of all arc volcanoes, so calculating an average for Java depends strongly on how representative these volcanoes are of the total volcanism on Java (which include more than 35 active volcanoes ${ }^{6}$ ). To calculate the most accurate average possible, we classified all the active volcanoes on Java as low-K, medium-K or high-K (on the basis of available data), and calculated a weighted mean of these classes using mafic data from the six volcanoes (two of which fell into each class). We agree that the average is sensitive to the weighting, but believe that the average is a fair representation of the average volcanic flux on Java, and is the appropriate value with which to compare to the average sediment input. The Java average is not significantly affected (less than $6 \%$ relative) by including nearby volcanoes on Bali, and so is not strongly dependent on the length of the arc sector chosen.

For most arcs, the individual volcanoes define a unique region in geochemical space (Fig. 2 of ref. 1), and a simple average of the volcanic data was sufficient to characterize the arc from a global perspective. Java is the exception, as is apparent from the attached figure. The correlations we presented in Fig. 3 of ref. 1 are not dependent on the Java point; the regression based on the other arcs is as good or better than the one that includes Java. Therefore Varne's concern about the validity of the averages from the other seven arcs should be assuaged.

We suggest, however, that even the Java average reflects its sediment input. Javanese volcanics possess robust geochemical features that are shared by the Indian Ocean sediments: both are global end-members in $\mathrm{Th} / \mathrm{Sr}$, and the $\mathrm{Ba} / \mathrm{Th}$ ratio for Java volcanics is distinctively low and fairly uniform. Other studies focused specifically on Indonesia have also found an important role for sediment recycling ${ }^{7-10}$.

1. Plank, T \& Langmuir C H Nature $362,739-743$ (1993)

. Wheller, G. E., Varne, R. . Foden, J. D. \& Abbott, M.J. J. Volcanol. Geotherm. Res. 32, 137-160 (1987).

3. Whitford, D. J., Nicholss, I. A. \& Taylor, S. R. Contrib. Mineral. Petrol. 70, 341-356 (1979)

Plank, T thesis (Columbia Univ. 1993)

5. Whitford, D. thesis (Australian National Univ. 1975)

6. Simkin, T etal Volcanoes of the World (Smithsonian Institution, Washington, DC, 1981)

. Whitford, D. J. \& Jezek, P. A. Geol. Soc. Am. Bull. 93 504-513(1982).

8. Stoiz, A. J. et al. Contrib. Mineral. Petrol 105, 585-601 (1990)

Edwards, C. M. H. et al Nature 362, 530-533 (1993)

10. Vroon, P. Zet al J. geophys. Res. (in the press)

11. Krein, E. M \& Langmuir, C. H. J. geophys. Res. 94. 4241-4254 (1989).

12. Langmuir, C. H. in Caltech Plume Symp. (Pasadena, 1991) 